\title{
Flexibility and Political Biases in Elections with Retrospective Voting
}

\author{
Robert C. Schmidt \\ Faculty of Business Studies and Economics, University of Kaiserslautern, Kaiserslautern, Germany \\ Email: robert.schmidt@wiwi.uni-kl.de
}

How to cite this paper: Schmidt, R.C. (2018) Flexibility and Political Biases in Elections with Retrospective Voting. Theoretical Economics Letters, 8, 1657-1664. https://doi.org/10.4236/tel.2018.810106

Received: March 7, 2018

Accepted: June 16, 2018

Published: June 19, 2018

Copyright $\odot 2018$ by author and Scientific Research Publishing Inc. This work is licensed under the Creative Commons Attribution International License (CC BY 4.0).

http://creativecommons.org/licenses/by/4.0/

\section{c) (i) Open Access}

\begin{abstract}
This paper characterizes the optimal degree of flexibility in a dynamic model where two candidates compete in elections repeatedly. Giving the winner of an election some flexibility to depart from an earlier campaign promise is crucial due to new information that can arrive after the election. However, too much flexibility implies that candidates follow primarily their own biases. It is shown that first-best policies can be implemented for any realization of the state in all periods, in spite of candidates' known biases. This is achieved via retrospective voting, by adjusting the probability of reelecting the incumbent to her implemented policy.
\end{abstract}

\section{Keywords}

Electoral Competition, Commitment, Campaign Promises, Punishment, Dynamic Game

\section{Introduction}

Flexibility of candidates or parties in office to respond to new information that arrives after an election is a crucial feature of a well-functioning democracy. However, this implies that the implemented policies may deviate from what the winning candidate announced before the election, in particular if the information that arrives after the election is neither observable nor verifiable by the voters. The downside of flexibility is that incumbents may primarily follow their own biases, rather than respond optimally to shocks that arrive after the election.

The literature is divided: many authors study Downsian ${ }^{1}$ electoral competition

${ }^{1}$ Downsian electoral competition games generally have the following structure. Two (or more) candidates or parties announce their policy platforms in the first stage of the game. In the second stage, voters elect one of the candidates. After the election, the winner implements her previously announced platform. 
models, abstracting from flexibility by assuming that after the election, winning candidates are committed to their policy platforms announced before the election. On the other hand, in models of "postelection politics", incumbents make policy choices once in office so that announcements made before an election are irrelevant. [1] argue that "It is thus somewhat schizophrenic to study either extreme: where promises have no meaning or where they are all that matters. To bridge the two models is an important challenge."

This paper helps to overcome this "schizophrenia", by assuming that a winning candidate can deviate from an earlier campaign promise after the election. However, such deviations are costly to the candidate. The cost is implicit in the probability that the incumbent is reelected in the next period ${ }^{3}$. I demonstrate that under plausible conditions, there exists an equilibrium where in each period, the winner responds optimally to information revealed after the election, thereby maximizing voters' utility, despite the candidate's own bias. This is achieved by "punishing" a candidate with a positive ("right-wing") bias for implementing rightist policies via a reduced reelection probability, while rewarding her for implementing leftist policies (vice versa for a candidate with a negative bias). In equilibrium, voters are indifferent between the two candidates in each period. Adjustments in the probability of reelecting the incumbent via retrospective voting, therefore, serve as a credible threat that can "discipline" candidates, while granting them sufficient flexibility to respond to new information after the election.

In the model, candidates are both office- and policy-motivated (see [2]). Hence, they care about winning the election and about the implemented policy. Biased preferences of candidates are considered by, among others, [3] who show that reputation can help to explain why campaign promises are often kept. Flexibility to deviate from campaign promises after the election is analyzed also by [4] who assumes that candidates' biases are private information. While the cost of deviating is exogenous in [4], I assume that it is implicit in voters' probability of reelecting the incumbent in the future. Retrospective voting is analyzed by [5] who consider the case where voters obtain private signals about the state of the world while parties are ignorant about $\mathrm{it}^{4}$. By contrast, I assume that candidates possess more information than voters and observe the state, while voters are ignorant about it (e.g., [8]). This reflects the idea that candidates have more ${ }^{2}$ While in Downsian electoral competition models, binding campaign promises are the central aspect (that may for example reveal candidates' private information about the true state of the world), models of postelection politics focus for instance on aspects such as candidates' true (policy) motivation or competence. Persson and Tabellini write: "Thus the role of elections is very different than in preelection models. Rather than directly selecting policies, voters select politicians on the basis of their ideology, competence, or honesty, or more generally, their behavior as incumbents." ([1], pp. 12-13).

${ }^{3}$ This cost, thus, arises endogenously as part of voters' equilibrium voting strategy. Any punishment that is credible must be compatible with players' optimization behavior in a subgame perfect Nash equilibrium. By contrast, an exogenous cost of deviating from a previously-made campaign promise would be difficult to justify.

${ }^{4}$ See also [6] and [7]. 
resources to get informed. For example, they can hire experts. Voters, by contrast, are lacking the time, money, or incentives to get informed about every conceivable policy issue (see [9], [10]). Retrospective voting as a way to hold politicians accountable for their actions while in office is analyzed by [11]. In contrast to the model presented in this paper, voters cannot observe the activities of the incumbent while in office. Therefore, they base their reelection decision only on their realized utility. In a model of "partisan politics" with (partially) ignorant voters, [12] find that the outcome departs more from the Downsian prediction if candidates are mostly office-motivated. By contrast, I find that candidates who are more office-motivated are easier to "discipline" than more policy-motivated candidates: the latter need stronger incentives to abstain from following their own bias when in office.

\section{Model}

Two candidates, $A$ and $B$, compete repeatedly for office in elections. The time horizon is infinite. There is a homogeneous electorate. Voters' utility in period $t$ is

$$
u\left(s_{t}-x_{t}\right)+\epsilon_{t}
$$

where $s_{t}$ is the state of the world that is revealed to the incumbent after the election, $x_{t}$ is the policy implemented by the winner of the election (the incumbent) after observing $s_{t}$, and $\epsilon_{t}$ is a shock. $u$ is twice continuously differentiable, concave, and attains its maximum at zero where $u(0)=0$. Hence, voters' bliss point in period $t$ is $s_{t}$. The state $s_{t}$ is drawn from some continuous distribution with support $[\underline{s}, \bar{s}]$. The expectation of $s_{t}$ is zero in each period and states are not correlated across periods. The shock $\epsilon_{t}$ is also drawn from some continuous distribution and has mean zero. Both $s_{t}$ and $\epsilon_{t}$ are unobservable to the voters. The presence of the shock $\epsilon_{t}$ makes it impossible for voters to infer the (exact) realization of $s_{t}$ from their utility realized in period $t$ and $s_{t}$. By contrast, candidates observe $s_{t}$. Candidate $i s$ utility in period $t$ is

$$
u\left(s_{t}+\alpha_{i}-x_{t}\right)+\epsilon_{t}+e_{i, t} W
$$

where $\alpha_{i}$ is the candidate's bias, $W>0$ is a fixed utility premium for winning office, and $e_{i, t}=1$ if candidate $i$ wins in period $t$ ( $e_{i, t}=0$ otherwise).

Before analyzing the dynamic game, it is instructive to consider a simpler, static version of the model.

\subsection{Static Model}

Suppose, the two candidates simultaneously choose policy platforms $a_{i} \in[\underline{s}, \bar{s}]$, $i \in\{A, B\}$ before the election. Voters observe the platforms and elect party $i$ with probability $\sigma_{i}\left(a_{A}, a_{B}\right)$. Then the state $s$ and shock $\epsilon$ are realized. After observing $s$, the winner implements policy $x$, that may deviate from her previously announced policy platform. Voters observe $x$ but not $s$ or $\epsilon$. Let us as- 
sume that voters can "punish" or "reward" the winner, depending on $x, a_{A}$, $a_{B}$, and their realized utility.

The punishment is denoted $P_{i} \quad\left(P_{i}<0\right.$ in case of a reward). The index $i$ ( $i \in\{A, B\}$ ) indicates that the punishment function may depend on the characteristic of the party, that is, its bias. $P_{i}$ is subtracted from the winner's utility after implementing policy $x$. By assumption, voters do not incur any benefit or cost from inflicting the punishment (or reward) on the incumbent, but are committed to implementing the punishment according to a pre-defined rule (see below). In the static model, we treat the functions $P_{A}$ and $P_{B}$ as exogenous objects that were chosen by society before the game is played. The goal is to determine how society would optimally design these functions so as to maximize voters' (expected) utility.

Due to the presence of the shock $\epsilon$, any punishment rule that explicitly depends on voters' realized utility cannot implement the first-best (i.e., $x=s$ ) for all realizations of the state. It turns out, however, that a simple punishment rule that only depends on the policy $x$ implemented by the incumbent after the election, is sufficient to eliminate the winner's tendency to follow her own bias, inducing her to implement $x=s$ for any realization of $s$ :

Lemma 1 The linear punishment rule $P_{i}(x)=\rho_{i} x$, where $\rho_{i}=-u^{\prime}\left(\alpha_{i}\right)$, induces the winner to choose $x=s$ for all realizations of $s$.

Proof of Lemma 1. After the election, the winner $i$ chooses $x$ to maximize

$$
u\left(s+\alpha_{i}-x\right)+\epsilon+W-P_{i}(x) .
$$

Using $P_{i}(x)=\rho_{i} x$, the first-order condition reads:

$$
u^{\prime}\left(s+\alpha_{i}-x\right)=-\rho_{i} .
$$

This yields:

$$
x=s+\alpha_{i}-\left(u^{\prime}\right)^{-1}\left(-\rho_{i}\right) .
$$

Setting $\rho_{i} \equiv-u^{\prime}\left(\alpha_{i}\right)$ then yields the desired result.

Lemma 1 reveals that to implement the first-best, it is not necessary to make punishments contingent on voters' realized utility or on candidates' policy announcements. A simple linear punishment rule that only depends on the (known) bias of the winner and on the implemented policy $x$, is enough. As a result, candidates' campaign promises $a_{A}$ resp. $a_{B}$ become irrelevant. Given the punishment rule $P_{i}(x)=\rho_{i} x$, the winner $i$ implements $x=s$ irrespective of $a_{i}$. In equilibrium, voters are indifferent between the two candidates, no matter what they announce before the election.

\subsection{Dynamic Game}

We now assume that voters can only punish or reward the current incumbent by lowering or raising the probability $\left(\sigma_{i, t+1}\right)$ of reelecting this candidate (retrospective voting). As long as voters are indifferent between the two candidates, they are free to choose $\sigma_{i, t+1}$ depending on the history of the game. 
We can build on our insights from the static model. Lemma 1 suggests that optimal policies may be implemented by making $\sigma_{i, t+1}$ depend linearly on $x_{t}$, and independent of campaign promises. Therefore, the stage where candidates announce their platforms before the election in period $t$, can effectively be removed from the model. Later we will argue that this is without loss of generality. As a working hypothesis, suppose there is an equilibrium where voters are indifferent between the two candidates in each period under the following "punishment strategy" of the voters:

$$
\sigma_{i, t+1}=\frac{1}{2}-e_{i, t} \rho_{i} x_{t}+\left(1-e_{i, t}\right) \rho_{-i} x_{t} .
$$

Hence, if $\rho_{i}>0$, voters punish the incumbent by lowering the probability of reelecting this candidate in the next period when $x_{t}>0$, and reward her with a higher election probability if $x_{t}<0$. If it is possible to specify $\rho_{A}$ and $\rho_{B}$ in such a way that the winner of the election implements the first-best in each period given (3), then voters are indifferent between the two candidates at the beginning of each period, and the assumed punishment strategies can indeed be implemented in equilibrium.

Let us focus on stationary equilibria where-apart from the dependency of $\sigma_{i, t+1}$ from $x_{t}$ and the identity of the incumbent in period $t$-strategies do not depend on the history of the game. If such an equilibrium exists, then in period $t$ the incumbent's discounted payoff when choosing $x_{t}$ is:

$$
u\left(s_{t}+\alpha_{i}-x_{t}\right)+\epsilon_{t}+W+\delta\left(\sigma_{i, t+1} V_{i}^{h}+\left(1-\sigma_{i, t+1}\right) V_{i}^{l}\right),
$$

where $\delta$ is the discount factor, and $V_{i}^{h}$ denotes candidate is discounted equilibrium payoff from the next period onwards if she wins in period $t+1$, while $V_{i}^{l}$ is the respective payoff if she loses the election next period. Maximizing the discounted payoff over $x_{t}$, thereby using (3), we obtain the first-order condition:

$$
u^{\prime}\left(s_{t}+\alpha_{i}-x_{t}\right)=-\delta \rho_{i}\left(V_{i}^{h}-V_{i}^{l}\right) .
$$

Similarly as in the Proof of Lemma 1, by setting

$$
\rho_{i}=-\frac{u^{\prime}\left(\alpha_{i}\right)}{\delta\left(V_{i}^{h}-V_{i}^{l}\right)},
$$

first-best policy choices $\left(x_{t}=s_{t}\right)$ are induced for any realization of the state $s_{t}$. With these values of $\rho_{A}$ and $\rho_{B}$, we thus obtain for the expected discounted payoff of candidate $i$ in period $t$ before the state is revealed, after winning resp. losing the election:

$$
\begin{gathered}
V_{i}^{h}=u\left(\alpha_{i}\right)+\delta\left(V_{i}^{h} / 2+V_{i}^{l} / 2\right)+W, \\
V_{i}^{l}=u\left(\alpha_{i}\right)+\delta\left(V_{i}^{h} / 2+V_{i}^{l} / 2\right) .
\end{gathered}
$$

Solving (7) and (8) for $V_{i}^{h}$ and $V_{i}^{l}$, we obtain:

$$
V_{i}^{l}=\frac{u\left(\alpha_{i}\right)}{1-\delta}+\frac{\delta}{1-\delta} \frac{W}{2},
$$


and

$$
V_{i}^{h}-V_{i}^{l}=W
$$

Using (9) in (6), we find:

$$
\rho_{i}=-\frac{u^{\prime}\left(\alpha_{i}\right)}{\delta W} .
$$

For example, when $u(z)=-z^{2} / 2$, then (10) simplifies to: $\rho_{i}=\alpha_{i} /(\delta W)$.

To assure that for all possible realizations of the state in period $t$, the above equilibrium can be implemented, the boundary conditions

$$
\left|\rho_{i}\right| \underline{s} \geq-1 / 2 \text { and }\left|\rho_{i}\right| \bar{s} \leq 1 / 2
$$

need to be satisfied for $i=A, B$, so that $\sigma_{i, t+1} \in[0,1]$ (see (3)). This restricts the support $[\underline{s}, \bar{s}]$ of the state $s$. It is easy to see that these boundary conditions are less restrictive for larger values of $W$ and $\delta$.

The following proposition summarizes the above findings:

Proposition 1 There exists an equilibrium in the dynamic game where the winning candidate in each period implements the first-best policy. The equilibrium is sustained by "punishment strategies" where voters adjust the probability of reelecting the incumbent in the next period to the policy implemented in the current period. These strategies are credible as voters are, on the path, indifferent between the two candidates in each period.

Condition (10) indicates that first-best policies are easier to implement when candidates are more office motivated, i.e., when $W$ is larger. Then the reelection probability $\sigma_{i, t+1}$ only needs to be raised or lowered slightly in order to deter the incumbent from following her own bias, while adjusting the policy optimally to the state. This is intuitive: if a candidate cares more about getting into office, she suffers more from a reduction in her reelection probability and will respond to such changes more strongly (the same holds for a higher discount factor). Re-introducing the possibility of making campaign promises before each election does not change the above results. If voters follow the punishment strategies (3) in combination with (10), the equilibrium characterized above (see Proposition 1) that implements the first-best in every period, remains unchanged. There is clearly no profitable deviation for voters from their equilibrium voting strategy, since their utility is maximized on the path. And given that voters ignore candidates' campaign promises in their voting decision, these choices become irrelevant also for the parties.

\section{Conclusions}

Giving the winner of an election flexibility to respond to new information that arises after the election, is a key feature of any well-functioning democracy. If the state of the world is not observable to the voters, while candidates can observe it, flexibility may create a tension between the candidate's own bias and her tendency to respond to new information after the election. This paper shows that such tension can be avoided via retrospective voting, by appropriately ad- 
justing the probability of reelecting the incumbent in the next period to the policy implemented today. Candidates who care relatively less about the implemented policy, and more about getting into office are easier to "discipline" than more policy-motivated candidates: the latter need stronger incentives to abstain from following their own bias.

This paper is the first step towards a theory of electoral competition where campaign promises matter, but it is not all that matters. In the model analyzed in this paper, deviations from a previously announced policy platform are costly to the winner of an election, but not infinitely costly so that some flexibility to adjust the implemented policy after the election remains. Such flexibility is crucial in the light of new information or shocks that may arrive after the election. From a practical point of view, the paper illustrates that in a well-functioning democracy, candidates or political parties should be held accountable for their campaign promises to some extent, in order to prevent them from following their own ideological biases. Yet, punishments for deviations after the election from earlier promises should be limited so that a sufficient degree of flexibility remains to respond to new information that may arrive after the election.

Future research may build on the-deliberately-simple model presented in this paper, and extend it to allow for example for private information of candidates regarding their ability or political motivation. As long as on the equilibrium path, voters are indifferent between the candidates with positive probability, the key feature of the model presented in this paper may be preserved, namely that via adjustments in the reelection probability (retrospective voting), an incumbent may be "disciplined" and, hence, deterred from following her own political bias when responding to a shock that arrives after the election.

\section{Financial Support}

The author would like to thank Renaud Foucart, Bård Harstad, Katinka Holtsmark, and Sarah Auster for valuable comments. Financial support by the Deutsche Forschungsgemeinschaft (SCHM 2692/1-1) is gratefully acknowledged.

\section{References}

[1] Persson, T. and Tabellini, G. (2000) Political Economics-Explaining Economic Policy. MIT Press, Cambridge.

[2] Callander (2008) Political Motivations. Review of Economic Studies, 75, 671-697.

[3] Aragonès, E., Palfrey, T. and Postlewaite, A. (2007) Political Reputations and Campaign Promises. Journal of the European Economic Association, 5, 846-884. https://doi.org/10.1162/JEEA.2007.5.4.846

[4] Banks, J.S. (1990) A Model of Electoral Competition with Incomplete Information. Journal of Economic Theory, 50, 309-325. https://doi.org/10.1016/0022-0531(90)90005-5

[5] Esponda, I. and Pouzo, D. (2017) Retrospective Voting and Party Polarization. Mimeo. https://economics.sas.upenn.edu/index.php/ier/issues/accepted-papers 
[6] Esponda, I. and Pouzo, D. (2017) Conditional Retrospective Voting in Large Elections, American Economic Journal: Microeconomics, 9, 54-75.

https://doi.org/10.1257/mic.20140283

[7] Feddersen, T. and Pesendorfer, W. (1997) Voting Behavior and Information Aggregation in Elections with Private Information, Econometrica, 65, 1029-1058. https://doi.org/10.2307/2171878

[8] Schultz, C. (1996) Polarization and Inefficient Policies. Review of Economic Studies, 63, 331-343. https://doi.org/10.2307/2297855

[9] Heidhues, P. and Lagerlöf, J. (2003) Hiding Information in Electoral Competition. Games and Economic Behavior, 42, 48-74. https://doi.org/10.1016/S0899-8256(02)00531-6

[10] Laslier, J.-F. and Van der Straeten, K. (2004) Electoral Competition under Imperfect Information. Economic Theory, 24, 419-446. https://doi.org/10.1007/s00199-003-0414-z

[11] Ferejohn, J. (1986) Incumbent Performance and Electoral Control. Public Choice, 50, 5-25. https://doi.org/10.1007/BF00124924

[12] Gul, F. and Pesendorfer, W. (2009) Partisan Politics and Election Failure with Ignorant Voters. Journal of Economic Theory, 144, 146-174.

https://doi.org/10.1016/j.jet.2008.04.005 